\title{
Localization and Quantification of Total UV Absorbing Compounds in Chinese EIm (Ulmus parvifolia)
}

\author{
Vanessa A. Ferchaud ${ }^{1,2}$, Yadong Qi ${ }^{1,2}$ and Kit L. Chin ${ }^{1}$ \\ 1. Southern University Agricultural Land-Grant Campus, Baton Rouge, LA, USA \\ 2. Department of Urban Forestry and Natural Resources, Southern University, Baton Rouge, LA, USA
}

It has been well documented in the literature that trees, including the scattered individual trees in sunny urban settings, reduce UV radiation in the vicinity, and urban tree greatly reduces UV irradiance when they obscure both the sun and sky view [1,2]. Broad-leaf tree leaves have been known to absorb about 90-95\% of UV-B (280-315 nm) radiation [3, 4]. Tree tolerance of UV-B stress depends on a balance between damage and both shielding and repair processes. In many plant species, the mechanism for shielding from UV-B damage is due to the accumulation of UV-absorbing compounds [5, 6] including flavonoids and phenolics that play an important role in plant defense. Sensitivity to UV-B is however species-specific [7] and related to the perennial growth form of trees [8]. Chinese elm (Ulmus parvifolia Jacq.) is native to China, Korea, and Japan. It is a small to medium-sized deciduous tree growing to $10-18 \mathrm{~m}$ tall with a slender trunk and crown. It is often used as a fast-growing shade tree that is also hardy enough to grow in harsh planting situations like parking lots, and in small planters along streets and in plazas or patios in urban settings [9]. The aim of this study was to quantify and visualize the change in UV absorbing compounds in Chinese elm leaves during leaf growth and development in a growing season. Leaf samples of Chinese elm were collected from the sunexposed portions at the terminal end, $10-50 \mathrm{~cm}$ of a branch; of five individual Chinese elm trees in spring (April), summer (August) and fall (November) in 2009 on Southern University and A\&M College campus in Baton Rouge, LA, USA.

The fresh leaves were sectioned into approximately $0.5 \mathrm{~mm} \times 0.5 \mathrm{~mm}$ squares pieces using a sharp razor and embedded on a specimen disc using OTC-compound (Jung Tissue Freezing Medium, Leica Microsystems) and placed in the chamber of a cryostat (Leica CM-1850 UV Microtome, Nussloch, Germany) for sectioning at $30 \mu \mathrm{m}$ thickness. Rapid freezing at a low temperature of $-20^{\circ} \mathrm{C}$ was utilized depending on leaf moisture content. One drop of $0.2 \%$ Naturstoffreagenz-A (NA) (from Sigma Aldrich, St. Louis, MO) [0.2\%, w/v, 0.2 $\mathrm{g}$ amino ethyl diphenyl boric acid in $100 \mathrm{ml}$ distilled water stock solution] was added to a slide and then covered with a glass cover slip. One drop of Phosphate buffer (from Sigma Aldrich, St. Louis, MO) [34 $\mathrm{mmol} / \mathrm{L}, \mathrm{pH} 6.6 @ 25^{\circ} \mathrm{C}$ ] was added to the slide and covered with a cover slip. Images were taken using the monochrome camera and bright field color camera with Leica DMI6000 B Inverted Research Automated Robotic Fluorescent Imaging Microscope, Cambridge, United Kingdom.

Three (3) sun-exposed leaves were randomly selected and one (1) round disc approximately $6 \mathrm{~mm}$ was punched from each leaf in the middle of the lamina away from the midrib. The discs were placed in a 1.5$\mathrm{mL}$ microfuge tube and homogenized with a teflon pestle using liquid nitrogen. One $\mathrm{mL}$ of acidified methanol $\left(\mathrm{CH}_{3} \mathrm{OH} ; \mathrm{H}_{2} \mathrm{O}: \mathrm{HCl}, 79: 20: 1\right.$, v/v) was then added to the 1.5-mL microfuge with the powdered disc and mixed homogeneously. Spectra of the extracts $(190-700 \mathrm{~nm})$ were obtained with a UV/Visible Genesys 6 Spectrophotometer (Thermo Electron Corporation).

The NA stained Chinese elm leaves showed that the wall-bound UV-absorbing compounds were rendered very bright and visible under monochrome camera in the spring sampled leaves (Fig. 1), showing UVabsorbing compounds were present primarily in leaf epidermal layers (upper and lower), main vein petioles, vascular bundles and palisade tissues in leaf cross-sections (Fig.1a, 1b). Figure 1c was a bright field color image of Chinese elm leaf petiole. Chinese elm fall samples leaves, however, showed wall-bound UV- 
absorbing compounds only readily visible in leaf epidermal layers and nearby palisade tissues, but not in the vascular bundles (Fig. 2, a,b,c), this may be due to leaf aging resulting in presence of more lignin and fibers in mature leaves. It was apparent that the NA stain method worked better for young leaves than mature leaves. This may be a limitation of the NA stain method. As such, we further used spectrophotometric method to quantify the seasonal change. The results indicated that there was a significant increase in the total UV-absorbing compounds from spring (April) to summer (August) leaves (Fig. 3). No significant difference was shown between summer and fall (November) leaves. The strategic locations and accumulation of UV absorbing compounds through the leaf development are important to plant self-defense against the cumulative exposure of the harmful solar UV-B radiation in Chinese elm [10].

References:

[1] G. M. Heisler \& R.H. Grant, Urban Ecosyst 4 (2000), p. 193.

[2] Na et al, Urban Forestry \& Urban Greening, 13 (2014) p. 785.

[3] D. J. Nowak \& G.M. Heisler, National Recreation and Park Association, 2010

[4] Y. Qi et al, in "UV Radiation in Global Change: Measurements, Modeling and Effects on Ecosystem", Springer-Verlag \& Tsinghua University Press, p. 509.

[5] de la Rosa et al, New Phytologist 150 (2001), p. 121.

[6] Jansen et al, Trends in Plant Science, 3 p. 131.

[7] Rozema et al, J Photoch Photobio B, 66 p. 2.

[8] S.S. Sedej, Acta Biologica Slovenica, 57 (2), p. 13.

[9] USDA-NRCS. 2009. Chinese Elm Plant Guide, The Plants database, National Plant Data Center, Baton Rouge, Louisiana.

[10] The authors acknowledge funding from USDA-NIFA Grant 2014-38821-22415.
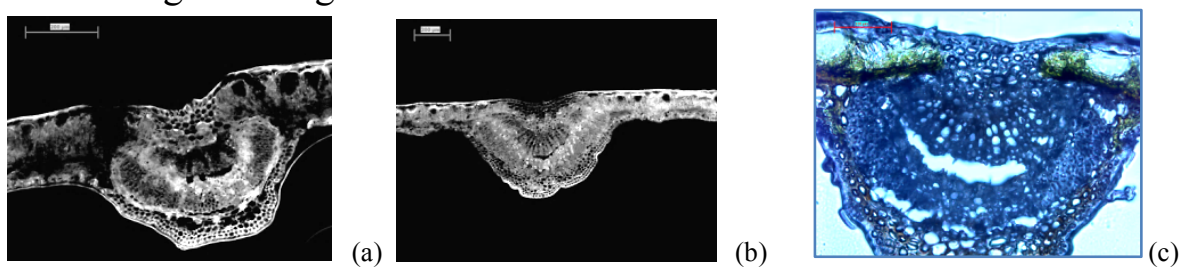

Figure 1. Visualization of UV absorbing compounds in young Chinese elm leaves collected in spring (April) taken with monochrome camera and stained with NA $(\mathrm{a}, \mathrm{b})$ and brightfield leaf petiole cross-section with phosphate buffer taken with color camera ( c)
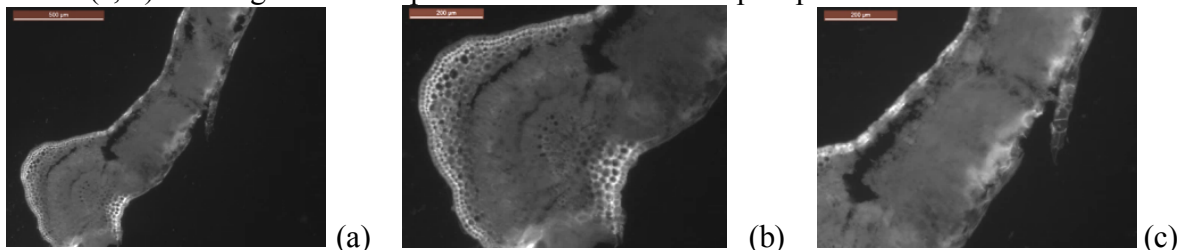

Figure 2. Visualization of UV absorbing compounds in mature Chinese elm leaves collected in summer (August) stained with NA in petiole and leaf cross-section ( $a, b \mathrm{c})$.

Figure 3. Quantification of leaf total UV absorbing compound content using a spectrophotometer in Chinese elm leaves collected in April, August, and November (Mean+1SD, n=5).

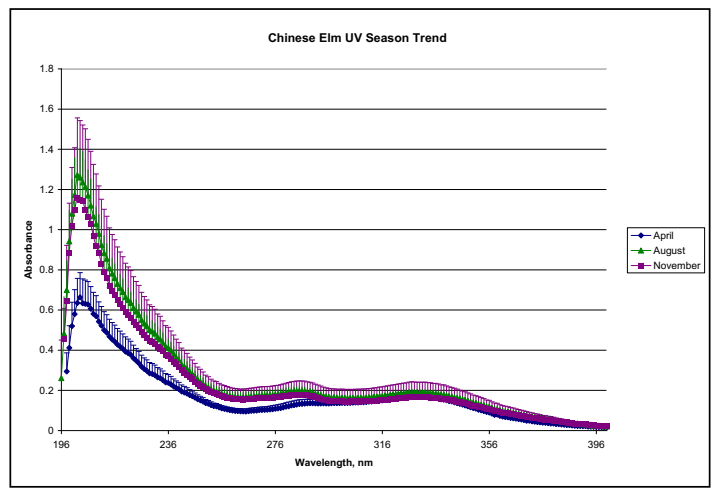

